(2) Open Access Full Text Article

ORIGINAL RESEARCH

\title{
Anterior Acute Uveitis Report in a SARS-CoV-2 Patient Managed with Adjunctive Topical Antiseptic Prophylaxis Preventing 2019-nCoV Spread Through the Ocular Surface Route
}

This article was published in the following Dove Press journal:

International Medical Case Reports Journal

\author{
Cosimo Mazzotta $\mathbb{D}^{1-4}$ \\ Ermete Giancipoli $\mathbb{D}^{5}$ \\ 'Department of Medicine, Surgery and \\ Neurosciences, Post-Graduate \\ Ophthalmology School, University of \\ Siena, Siena, Italy; ${ }^{2}$ Departmental \\ Ophthalmology Unit, Alta Val d' Elsa \\ Hospital, Siena, Italy; ${ }^{3}$ Ophthalmology \\ Operative Unit, Casentino Hospital, \\ Arezzo, Italy; ${ }^{4}$ Siena Crosslinking Center, \\ Siena, Italy; ${ }^{5}$ Ophthalmology Unit, Vito \\ Fazzi Hospital, Lecce, Italy
}

Purpose: To report the clinical-epidemiological association between acute anterior uveitis and acute bilateral follicular conjunctivitis in a 30-year-old female patient who had tested positive for the SARS-CoV-2 RT-PCR.

Methods: A 30-year-old female visited emergency ophthalmology care at the Siena Crosslinking Centre, Italy, for a bilateral eye redness lasting two weeks, associated with unilateral photophobia and blurred vision in her right eye. She visited on the $23 \mathrm{rd}$ of March 2020 in the full pandemic period and presented chills and fever with a temperature of $39.0^{\circ} \mathrm{C}$, associated with complete loss of taste. Since eye examination findings, systemic symptoms and epidemiological criteria correlated with SARS-CoV-2 infection, she was referred to Siena University Hospital, Italy, for the SARS-CoV-2 nasopharyngeal buffer and haematological examinations for uveitis.

Results: Eye examination revealed bilateral conjunctival hyperaemia with acute follicular conjunctivitis associated with right eye acute anterior uveitis characterized by diffuse pigmentary and whitish immune precipitates over the anterior capsule of the crystalline lens and initial anterior lens opacity explaining the blurred vision. Adjunctive prophylactic eye topical treatment, included in the acronym SHYPIO $(0.02 \%$ sodium hypochlorite solution, $0.6 \%$ povidone iodine eye-drops and $10.50 \%$ ozonized oil eye-drops), was associated with conventional uveitis therapy to prevent the virus spread through the ocular surface route.

Conclusion: Our report demonstrates that complicated acute anterior uveitis (iridocyclitis) with blurred vision could be associated with SARS-CoV-2 infection, being potentially sightthreatening for early complicated lens opacity. Ophthalmologists examining suspected or asymptomatic patients should be aware of the risk of 2019-nCoV infection.

Keywords: SARS-CoV-2 uveitis, SARS-CoV-2 anterior uveitis, SARS-CoV-2 associated uveitis, SARS-CoV-2 conjunctivitis, COVID-19 uveitis, COVID-19 conjunctivitis

\section{Introduction}

Since emerging from China in December 2019, coronavirus disease 2019 (COVID19) has become a global pandemic. This disease is caused by severe acute respiratory syndrome, coronavirus 2 (SARS-CoV-2). ${ }^{1,2}$ There have been several reports addressing that follicular conjunctivitis is the most common ocular manifestation of SARS-CoV-2 infection. ${ }^{3-7}$ On the 30 January 2020 the World Health Organization (WHO) declared COVID-19 a public health emergency of
Correspondence: Cosimo Mazzotta Siena Crosslinking Center, Via Sandro Pertini 7, Monteriggioni, Siena, Italy Tel +393495550676

Email cgmazzotta@libero.it
International Medical Case Reports Journal 2020:13 513-520 
international concern (PHEIC). ${ }^{1}$ At the time of this article revision, the WHO recorded 7.690 .708 confirmed global COVID-19 cases and 427.630 deaths. Italy was among the first to be hard-hit ${ }^{2}$ by SARS-CoV-2, with recorded 167 deaths among Doctors to date. The COVID-19 disease is not only spreading worldwide, but also, unfortunately, wreaking havoc among hospital staff, including doctors and nurses. ${ }^{7,8}$ Recommendations for ophthalmologists 9 include wearing facial masks and goggles, or face visors and slit lamp shields together with hand gloves for protection against ocular transmission of the SARS-CoV-2, which has recently been detected in the pre-corneal tear film. $^{4-6}$ The severe acute respiratory syndrome Coronavirus-2 (SARS-CoV-2) ${ }^{1}$ is a novel, enveloped, single-stranded RNA beta coronavirus identified as a member of the Coronaviridae family - subfamily Orthocoronaviridae and order Nidovirales ${ }^{1}$ that causes COVID-19; originally linked to an outbreak in Wuhan of China's Hubei province. ${ }^{10}$ Direct contact with mucous membranes, including the eye, is one of the documented transmission routes beyond the main routes of the nose and mouth through saliva droplets and direct or indirect contact with the body fluids. ${ }^{3-7}$ A study ${ }^{11}$ conducted during the 2003 severe acute respiratory syndrome (SARS) outbreak detected SARS-CoV-1 in SARS patients' tear samples. ${ }^{12}$ Compared with SARS-CoV-1, SARS-CoV-2 has a similar binding receptor and comparable phylogenetic and structural features which also share similar systemic and epidemiological characteristics. ${ }^{13}$ Lack of eye protection $^{3}$ was found to be a primary risk factor of SARS-CoV-2 transmission from SARS patients to doctors and nurses, warning that respiratory illness could also be transmitted through ocular secretions and conjunctiva. ${ }^{8}$ Similar concerns have been raised with SARS-CoV-2, especially among ophthalmologists and eye-care providers, as well as those on the front lines triaging what could be initial symptoms of COVID-19 or completely asymptomatic people with no fever or respiratory symptoms. ${ }^{9,10}$ Since conjunctivitis is the most commonly described eye condition both in early ${ }^{5}$ and late $e^{4,9,10}$ COVID-19 cases, ophthalmologists could easily be the first medical professionals to evaluate a patient with COVID-19. ${ }^{14}$ Indeed, the first doctor who denounced the spread of Coronavirus in Chinese patients was $\mathrm{Li}$ Wenliang, MD, a brilliant ophthalmologist. Unfortunately, Dr Wenliang died from COVID-19 and was believed to have contracted the virus from an asymptomatic glaucoma patient in his clinic. ${ }^{14}$ It is not anecdotal
Table I SHYPIO Protocol: Active Principles and Dosage

\begin{tabular}{|c|c|}
\hline $\begin{array}{l}\text { SHYPIO Protocol Active } \\
\text { Principles }\end{array}$ & Dosage \\
\hline $\begin{array}{l}\text { Sodium Hypochlorite }(\mathrm{HOCl}) \\
0.02 \% \text { solution }\end{array}$ & $\begin{array}{l}\text { Nebulized } 2 \text { times } x \text { day on the } \\
\text { eyelids and eyelid rhyme }\end{array}$ \\
\hline $\begin{array}{l}\text { Povidone-lodine (PVP-I) } 0.6 \% \\
\text { eye-drops }\end{array}$ & $\begin{array}{l}\text { Administered } 2 \text { times } x \text { day }(5-10 \\
\text { min before and after Contact Lens } \\
\text { removal in CL wearers) }\end{array}$ \\
\hline $\begin{array}{l}\text { Ozonized oil }\left(\mathrm{O}_{3} \text {-Oil) } 10.50 \%\right. \\
\text { liposomes plus HPMC eye- } \\
\text { drops }\end{array}$ & $\begin{array}{l}\text { Administered } 3 \text { times } x \text { day (usable } \\
\text { with Contact Lenses on) }\end{array}$ \\
\hline
\end{tabular}

that ophthalmologists, dentists and otolaryngologists are at greater risk to contract the infection since they work a shorter distance from patients' mouth, nose and eyes. ${ }^{9}$ Unfortunately, as no specific therapies are available for SARS-CoV-2 and there is not yet a vaccine or effective antiviral drug, recognizing the common characteristics between SARS-CoV-2 and SARS-CoV- $1,{ }^{13}$ we introduced the adjunctive use of a precautionary multi-acting eye topical treatment named SHYPIO (Sodium Hypochlorite Povidone-Iodine Ozonized oil) in our clinical practice protocol, to prevent the spread of the virus through the ocular route of transmission, whose active principles and dosage are reported in Table 1 . The eye prophylaxis included a $0.02 \%$ sodium hypochlorite solution for the periocular skin and eyelid rhyme, in consideration of its antiviral activity against SARS-CoV-2, ${ }^{15}$ and available in ophthalmology for the therapy of blepharitis, ${ }^{16} 0.6 \%$ Povidone-Iodine (PVP-I) eye-drops ${ }^{17}$ for patients with acute follicular conjunctivitis based on its recognized efficacy (equivalent to $70 \%$ ethanol) inactivating SARS-CoV$1,{ }^{18}$ according to the common structural characteristics of SARS-CoV-1 and SARS-CoV-2, ${ }^{13}$ and $10.50 \%$ Ozonized oil eye-drops ${ }^{19,20}$ with lubricant and ozone-mediated biocidal activity. ${ }^{21,22}$ Antiseptics were also used in the pandemic for contact lenses wearers affected by high myopia, cases with severe keratoconus, poor visual acuity not suitable with sufficient spectacles correction, healthcare professionals and eye-care practitioners that could also be guaranteed a higher level of protection from the risk of infection through the reduction of the ocular surface viral load. We report a clinical case of a male patient with bilateral acute follicular conjunctivitis and acute unilateral sight-threatening uveitis who tested positive for the 
SARS-CoV-2 RT-PCR, in which the multi-acting ocular antisepsis has been associated with conventional therapy.

\section{Case Report}

A 30-year-old female patient come to our observation in emergency ophthalmology care at the Siena Crosslinking Centre, Italy, for a bilateral eye redness lasting two weeks, associated with unilateral photophobia and blurred vision in her right eye. She visited on the 23 March 2020 in the full pandemic period and presented chills with a temperature of $37.0^{\circ} \mathrm{C}$ that was increasing, associated with loss of taste, headache, fatigue and insomnia, without dyspnea. She notified us by phone that the day after the visit her temperature was above $39^{\circ} \mathrm{C}$. The ocular symptoms are displayed in Table 2.

The ocular anamnesis excluded previous episodes of uveitis, ocular and systemic infections or autoimmune diseases. Ophthalmological history proved that she has had annual check-ups for a mild myopia of - 2.5 Dioptres (D) in both eyes, without any other remarkable ocular pathologies. She had initially developed acute bilateral eye redness about two weeks before our visit, which was managed with antibiotics eye-drops after an ophthalmological telephone consultation, but reporting a progressive subjective worsening. After 2 weeks she reported a visual drop in the right eye so we decided to visit her because of the visual decay, and also because she was afraid to go to the Hospital due to the COVID-19 pandemic. Corrected Distance Visual Acuity (CDVA) of the right eye was 20/30 with - 2.75 D sphere and blurred vision, CDVA of the left eye was 20/20 with 2.75 D spherical spectacle correction. Slit lamp examination, Figure 1, revealed a diffuse conjunctival hyperaemia, Figure 1A, with acute follicular conjunctivitis (Figure 1B), that was associated with right eye acute anterior uveitis characterized by diffuse pigmentary and whitish (reasonable of immune inflammatory origin) precipitates over the anterior capsule of the crystalline lens and initial anterior lens opacity (Figure $1 \mathrm{C}$ and D) that well explained the blurred vision. A mild miosis was present in the right eye and the cornea was not impacted by keratic precipitates, with mild anterior chamber flare reaction, Table 2.

Ocular tension was within normal limits, anamnesis and bilateral gonioscopy excluded iris defects and pigmentary dispersion syndrome. The ocular fundus examination was unremarkable. Our clinical diagnosis, beyond bilateral acute follicular conjunctivitis, was of acute anterior nongranulomatous uveitis of suspected infectious (viral) and immune-related origin, that was rapidly being complicated
Table 2 Symptoms and Ocular Signs

\begin{tabular}{|l|l|}
\hline $\begin{array}{l}\text { Eye and Systemic } \\
\text { Symptoms }\end{array}$ & Ocular Signs \\
\hline Photophobia & Conjunctival Hyperaemia \\
\hline $\begin{array}{l}\text { Blurred vision in the Right } \\
\text { Eye }\end{array}$ & $\begin{array}{l}\text { Right Eye CDVA 20/30 with - 2.5 D } \\
\text { Sphere }\end{array}$ \\
\hline Lachrymation & Miosis \\
\hline Loss of taste & Pigmentary and Whitish Precipitates \\
\hline Fatigue & Aqueous Humour Flare \\
\hline Insomnia & Sub-Tarsal Follicular Hypertrophy \\
\hline Fever $39 \mathrm{C}^{\circ}$ & Anterior Lens Deposits and Opacity \\
\hline
\end{tabular}

by anterior lens opacity with pigmentary and whitish inflammatory deposits as clearly shown in Figure 1.

The patient was referred to Siena University Hospital, Italy, for the SARS-CoV-2 nasopharyngeal buffer and underwent haematological examinations for uveitis. Waiting for the results of the laboratory tests, whose most relevant are reported in Table 3, we decided to start a topical therapy, evaluating early clinical response prior to deciding on more invasive diagnostic manoeuvres such as aqueous humour sampling. The topical therapy included mydriatic eye-drops (tropicamide $10 \mathrm{mg} / \mathrm{mL}$ solution, Visumidriatic ${ }^{\circledR}$, Visufarma, Rome, Italy) 3 times daily in prevention of synechiae, reducing the ocular inflammation, and a fixed antibiotic-steroidal association 3 times daily ( $0.5 \%$ chloramphenicol plus $0.2 \%$ betamethasone) eyedrops (Betabioptal ${ }^{\circledR}$ suspension, Thea Pharma, Milan, Italy). Moreover, in order to expand the biocidal spectrum to viruses we decided to include in the treatment protocol some antiseptics, approved and available in the market for ophthalmic use, such as $0.02 \%$ sodium hypochlorite $(\mathrm{HOCl})$ preserved solution (Septavis ${ }^{\circledR}$, Medivis, Catania, Italy) nebulized on the periocular skin 2 times daily reducing the eyelid rhyme viral load, ${ }^{15,16} 0.6 \%$ PVP-I eyedrops (Iodim ${ }^{\circledR}$, Medivis, Catania, Italy) administered 2 times daily ${ }^{17,18}$ and antiseptic lubricants based on $10.50 \%$ ozonized oil eye-drops with liposomes (Ozodrop ${ }^{\circledR}$, FB Vision, Ascoli Piceno, Italy) administered 3 times daily. ${ }^{19-22}$

The clinical symptoms regressed completely in 4 weeks and at the one-month follow-up visit, as clearly documented in Figure 2, the pigmentary deposits and diffuse whitish inflammatory opacities of the anterior 


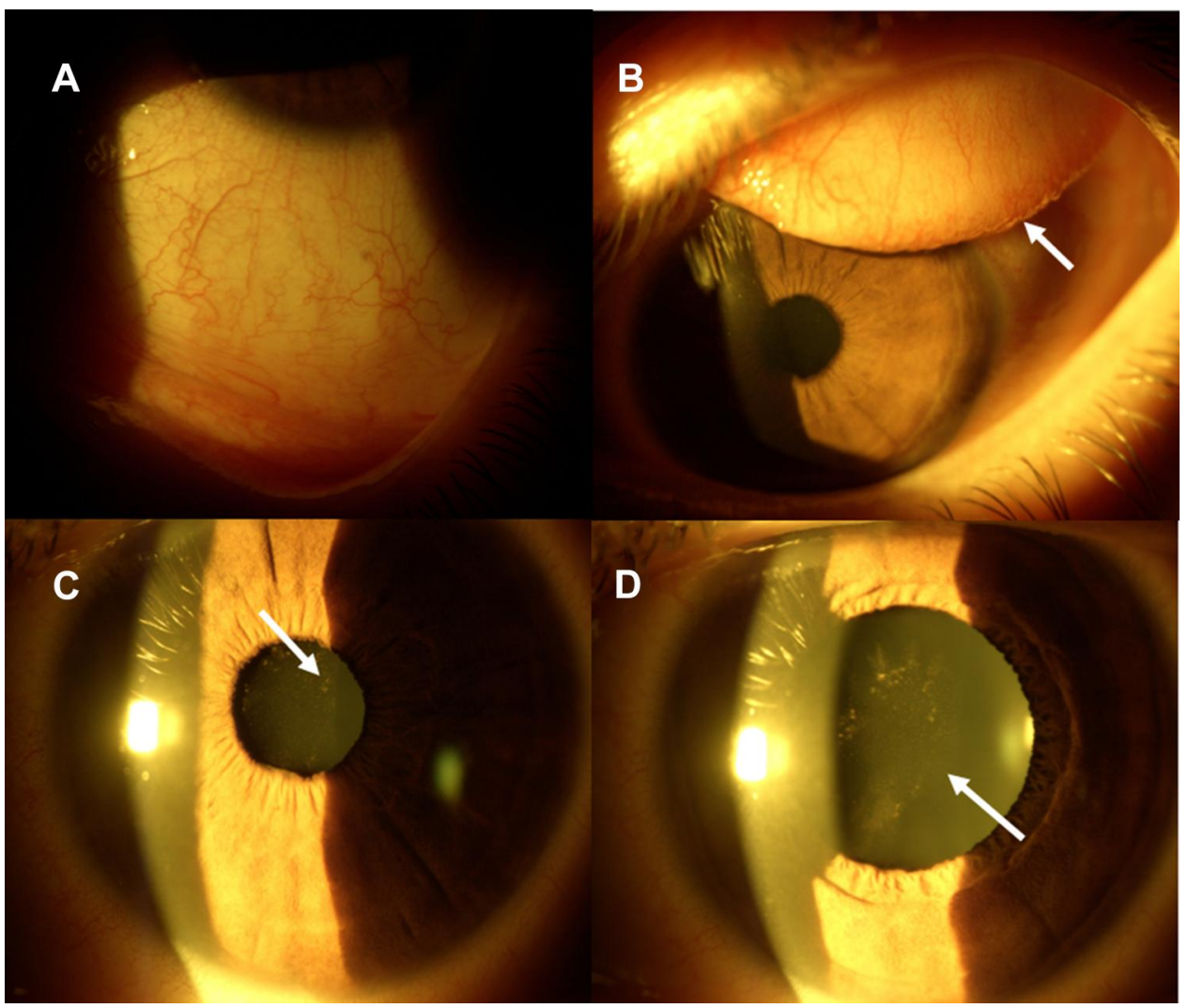

Figure I SARS-CoV-2 Anterior Uveitis. Conjunctival diffuse hyperaemia (A) Acute Follicular conjunctivitis with sub-tarsal follicular hypertrophy ((B) white arrow). Mild miosis with pigmentary acute anterior uveitis $(\mathbf{C})$ white arrow). After pharmacological mydriasis, pigmentary and whitish inflammatory precipitates on the anterior capsule of the crystalline lens with initial lens opacity were evident ((D) white arrow).

capsule of the crystalline lens documented in miosis $(2 \mathrm{~A})$ and after pharmacological mydriasis $(2 \mathrm{~B})$ disappeared totally, as evidenced at biomicroscopic examination, thus clearing the anterior capsule, as well documented in miosis (2 C) and after pupil dilatation (2 D), after a one-month topical therapy. The patient was excited at the follow-up visit because her visual acuity returned to $20 / 20$ with 2.75 D myopic spherical correction, in absence of ocular surface inflammation.

The laboratory data, as reported in Table 3, excluded HLA B27 positivity, Lupus Anti-Coagulant (LAC), TORCH (toxoplasmosis, rubella, cytomegalovirus, herpes simplex, Epstein Barr and HIV complex antibodies), AntiNuclear-Antigen (ANA) and Extractable-NuclearAntigens (ENA) associated uveitis. On the contrary, there were some of the common laboratory findings of COVID-19 such as early leukopenia. ${ }^{26}$ The patient tested positive for SARS-CoV-2 from the nasopharyngeal swab using RT-PCR, available $24 \mathrm{~h}$ later, and confirmed the infection of the SARS-CoV-2 virus showing a cycle threshold (Cts) value of 22, indicating a high presence of nucleic acid in the sample. The patient was instructed to self-quarantine for 4 weeks, followed-up by telephone, and revisited at the Siena Crosslinking Centre, Italy, for the one-month follow-up. Patient gave her written informed consent to have the case details and accompanying images published. The institutional review Board of the Siena Crosslinking Center approved the publication of the case details.

\section{Discussion}

To the best of our knowledge, this is the first international clinical report of acute anterior uveitis associated with follicular conjunctivitis in a patient who tested positive for SARS-CoV-2. Eye examination findings correlated with SARS-CoV-2 described bilateral mild follicular conjunctivitis, unilateral or bilateral bulbar conjunctiva injection, follicular reaction of the sub-tarsal palpebral conjunctiva, lachrymation and mild eyelid oedema. Coronaviruses (CoVs) are capable of producing a wide spectrum of ocular manifestations from anterior segment pathologies like conjunctivitis and anterior uveitis to sight- 
threatening conditions like retinitis and optic neuritis. ${ }^{23-25}$ Looking at the retinal degeneration in the experimental coronavirus retinopathy (ECOR) model,${ }^{24}$ the impression is given that coronavirus creates two different phases: the first represented by the primary infection which induces the triggering of the immune system, while the second phase is likely to be an autoimmune disease. ${ }^{25}$

Our report demonstrates that complicated acute anterior uveitis (iridocyclitis) with blurred vision could be associated with SARS-CoV-2 infection, being potentially sight-threatening for early complicated lens opacity. What we actually know is that respiratory viruses are capable of inducing ocular complications through droplets, both in early symptomatic and asymptomatic infected patients, which then leads to severe respiratory infection with pneumonia and dyspnea. Despite ocular manifestations of the SARS-CoV-2, such as conjunctival hyperaemia, chemosis and lachrymation, which were reported in those with more severe systemic manifestations and respiratory symptoms, ${ }^{10}$ some studies reveal the possibility of a direct or indirect trans-conjunctival mucous

Table 3 Relevant Laboratory Test Results are Indicated with *. Cts $<29$ are Strong Positive Reactions Indicative of Abundant Target Nucleic Acid in the Sample. At Real Time PCR Assay the Cts $<29$ are Strong Positive Reactions Indicative of Abundant Target Nucleic Acid in the Sample; Cts of $30-37$ are Positive Reactions Indicative of Moderate Amounts of Target Nucleic Acid and Cts of 38-40 are Weak Reactions Indicative of Minimal Amounts of Target Nucleic Acid Which Could Represent an Infection State or Environmental Contamination

\begin{tabular}{|l|l|}
\hline Relevant Laboratory Tests & Results \\
\hline $\begin{array}{l}\text { SARS-CoV-2 Real Time-PCR Ct } \\
\text { value }\end{array}$ & $\begin{array}{l}22^{*} \mathrm{Ct} \text { (cycle threshold) }<29 \\
\text { strong positive }\end{array}$ \\
\hline Neutrophils & $\begin{array}{l}1.25^{*} \text { (normal value range 2-8) } \\
10^{\wedge} 3 / \mu \mathrm{L}\end{array}$ \\
\hline Monocytes & $\begin{array}{l}0.13^{*}(\text { normal value range } 0.16- \\
1.0) 10^{\wedge} 3 / \mu \mathrm{L}^{\wedge}\end{array}$ \\
\hline Leucocytes & $\begin{array}{l}3.0^{*}(\text { normal value range 4-II.0) } \\
10^{\wedge} 3 / \mu \mathrm{L}\end{array}$ \\
\hline C 3 (complement) fraction & $\begin{array}{l}78^{*}(\text { normal range } 90-180 \\
\text { woman) } \mathrm{mg} / \mathrm{dl}\end{array}$ \\
\hline HLA B 27 & Negative \\
\hline Ab Anti-BORRELIA, VDRL & Negative \\
\hline Reuma test, ANA, ENA, ANCA, & Negative \\
\hline Lupus AC & Negative \\
\hline TORCH complex antibodies & \\
\hline
\end{tabular}

membrane transmission in the mild manifestation of the disease. $^{5,6}$ The fact that exposed mucous membranes and unprotected eyes increase the risk of SARS-CoV-2 transmission, suggesting that incautious exposure of unprotected eyes to $2019-\mathrm{nCoV}$ could cause acute respiratory infection. ${ }^{3}$ Ophthalmologists examining suspected cases and/or asymptomatic patients should be aware of the risk of 2019-nCoV infection, wear protective eyewear, use gloves, avoid touching their mouth, nose and eyes. ${ }^{7,10}$

The association of acute anterior uveitis in a patient with acute bilateral follicular conjunctivitis who tested positive to RT-PCR for SARS-CoV-2 and had typical clinical symptoms, leukopenia ${ }^{26}$ and met the epidemiological criteria, was considered adequate for the hypothesis of a SARS-CoV-2 correlated uveitis; also based on the biological plausibility principles recently recalled in the Editorial by Parrish $\mathrm{RK}^{2 \mathrm{nd}} .{ }^{14}$ The presence of the virus in tears ${ }^{6}$ was not tested considering the pandemic risk and the positivity of the patient to RT-PCR for SARS-COV-2. Detection of SARS-CoV-2 RNA in aqueous humour was postponed to clinical evaluation of early therapeutic response, thus avoiding invasive manoeuvres, and was also refused by the patient during the pandemic. In recognition of the common phylogenetic and structural characteristics of SARS-CoV-2 with SARS-CoV- $1,{ }^{13}$ and the proved efficacy of PVP-I in reducing viral activity of SARS-COV $-1,{ }^{18}$ we introduced the use of $0.6 \%$ PVP-I eye drops recently tested for ophthalmic use. ${ }^{17}$ Povidoneiodine (PVP-I) products have been extensively used for the disinfection of various bacteria and viruses for years because of their strong bactericidal and antiviral activities. $^{17,18}$ The free-iodine released from the PVP-I complex performs its biocidal activity by acting directly on the external membranes of microorganisms, oxidizing their proteins and leading to the death of pathogens. The treatment of SARS-CoV-1 with PVP-I products for 2 minutes reduced virus infectivity from $1.17 \times 10^{6}$ $\mathrm{TCID}_{50} / \mathrm{mL}$ to below the detectable level. The efficacy of PVP-I products was equivalent to $70 \%$ ethanol. ${ }^{18}$ In recent reports, ${ }^{15,16}$ evaluating the persistence of coronaviruses on inanimate surfaces and their inactivation with biocidal agents, analysis revealed that human CoVs such as SARS-CoV-1, the Middle East Respiratory Syndrome (MERS) coronavirus or endemic human coronaviruses $(\mathrm{HCoV})$ can persist on inanimate surfaces like metal, glass or plastic for up to 9 days, but can be efficiently inactivated by surface disinfection procedures with $62-$ $71 \%$ ethanol, $0.5 \%$ hydrogen peroxide or $0.1 \%$ sodium 


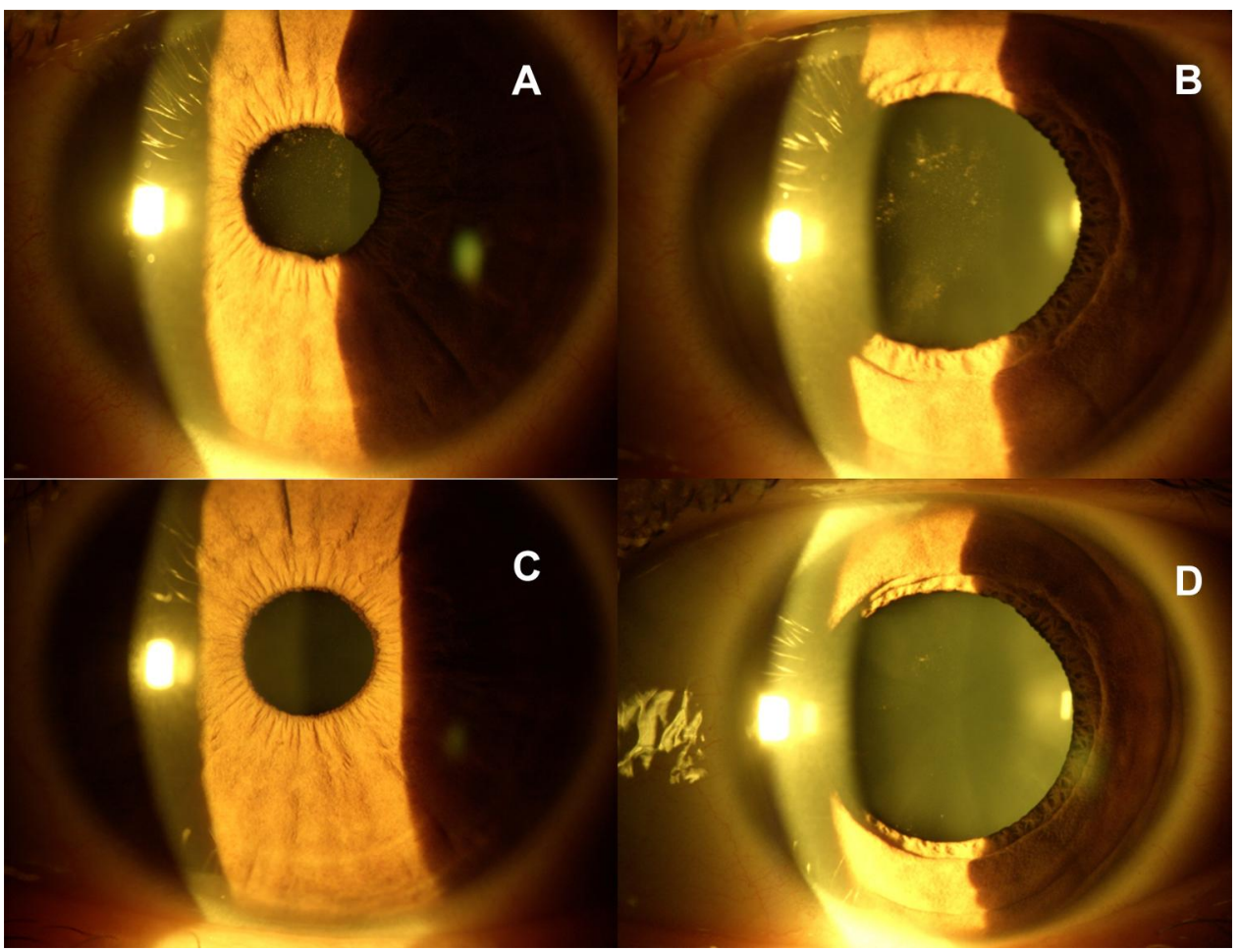

Figure 2 SARS-CoV-2 Anterior Uveitis. Mild miosis with pigmentary acute anterior uveitis (A) before treatment. Pigmentary and inflammatory whitish precipitates on the anterior capsule of the crystalline lens with initial lens opacity (B) after pupil dilatation, before the therapy. Biomicroscopic evidence of cleared anterior capsule of the crystalline lens in miosis (C) and in mydriasis (D) with the disappearance of pigmentary and diffuse whitish inflammatory deposits after combined topical therapy.

hypochlorite within 1 minute. The results showed that instant hand wiping using a wet towel soaked in water containing $1.00 \%$ soap powder, $0.05 \%$ active chlorine, or $0.25 \%$ active chlorine from sodium hypochlorite removed $98.36 \%, 96.62 \%$, and $99.98 \%$ of the virus from hands. ${ }^{15,16}$ Eyelid rhyme antisepsis was proposed to reduce the periocular skin viral load by using a $0.02 \%$ nebulized sodium hypochlorite solution, recently available for blepharitis therapy similar to Avenova ${ }^{\circledR}$ (NovaBay Pharmaceuticals, Inc., Emeryville, CA, USA). Sodium hypochlorite preserved $0.01 \%$ saline solution has been shown to reduce all the species present in the eyelid rhyme (Gram +, Gramand spores), the same which then colonize the conjunctiva of the patient. In fact, from the study carried out on $\mathrm{HOCl}$ it has emerged that at this concentration it is able to strongly reduce the microbial load (by 90\%) without causing the loss of commensal bacterial species after just a few minutes, thus maintaining a beneficial correlation between them and the guest. ${ }^{16}$

An adjunctive eye-lubricant with potential biocidal activity was included in the therapeutic regimen based on ozone in the form of ozonized oils (O3-Oil), obtained from the chemical reaction between ozone and unsaturated fatty acids of vegetable oils. ${ }^{19-21}$ It is well documented in scientific literature that ozone-oxygen mixtures inactivate microorganisms, including bacteria, fungi and viruses. ${ }^{22}$ Ozone-mediated virus inactivation occurs primarily in two ways: by lipid peroxidation and by protein peroxidation. Virus inactivation by ozone delivery strongly suggests damage and destruction of the lipid viral envelope and protein capsid. ${ }^{27-30}$

The sensitivity of lipid-containing viruses to ozone in these studies suggests that enveloped viruses may lose infectivity through lipid peroxidation. ${ }^{22} \mathrm{CoVs}$ also have abundant cysteine in their spike proteins ${ }^{27,28}$ that may be easily and safely exploited with ozone (or other oxidation) therapy. Ozone's ability to inactivate cysteine dependent proteins was reported as an ozonides attack on cysteinedependent papain, believed to inactivate the enzyme by oxidizing the active sulfhydryl group to sulfenate or sulfenic acid. ${ }^{22,27,30}$ Interestingly, in spite of its instability, the ozone molecule can be stabilized for topical use as an ozonide between the double bonds of a monounsaturated fatty acid such as oleic acid. ${ }^{19,20}$

In conclusion, since December 2019 the coronavirus disease 2019 (COVID-19) emerging from China has become a global pandemic caused by severe acute respiratory syndrome coronavirus 2 (SARS-CoV-2); and there 
have been several reports addressing that conjunctivitis is the most common ocular manifestation of SARS-CoV-2 infection. However, to the best of our knowledge, we report the first clinical-epidemiological association between acute anterior uveitis complicated by crystalline lens anterior capsule opacity with bilateral follicular conjunctivitis in a patient who tested positive for SARS-CoV2 RT-PCR, paving the way to a potential SARS-CoV-2 associated sight-threatening ocular diseases.

The adjunctive adoption to acute anterior uveitis therapy of a multi-acting prophylactic eye topical treatment, whose active principles are included in the acronym SHYPIO for $0.02 \%$ Sodium Hypochlorite solution, $0.6 \%$ Povidone Iodine eye-drops and $10.50 \%$ Ozonized Oil eye-drops, could further reduce the potential spread of the SARS-CoV-2 disease through the ocular surface route. Ophthalmologists examining suspected cases and/or asymptomatic patients should be aware of the risk of 2019-nCoV infection and should always wear protective eyewear, use gloves and avoid touching their face, mouth, nose and eyes. In this critical phase of evolving knowledge, it is important to generate evidence to address unanswered questions regarding the safety and efficacy of any potential treatment against COVID-19 and SARS-CoV-2 diffusion; so whenever possible, treatments must be studied in well-designed, controlled clinical trials. In the meantime, as we look for definitive answers, expert opinions, clinical reports and scientifically supported recommendation on therapies and prophylactic drugs based on the principle of biological plausibility are extremely important guidance.

All case reports must include a statement confirming that written informed consent has been provided by the patient to have the case details and any accompanying images published. Please ensure you include such confirmation in your revised manuscript.

\section{Acknowledgments}

The authors thank Dr. Jennifer Anne Berkley for the English revision.

\section{Disclosure}

The authors declare no conflicts of interest, no funding, and no support for this work.

\section{References}

1. Cascella M, Rajnik M, Cuomo A, Dulebohn SC, Di Napoli R. Features, Evaluation and Treatment Coronavirus (COVID-19). Treasure Island (FL): StatPearls Publishing; 2020. StatPearls [Internet].
2. Remuzzi A, Remuzzi G. COVID-19 and Italy: what next? Lancet. 2020;395(10231):1225-1228. doi:10.1016/S0140-6736(20)30627-9

3. Lu CW, Liu XF, Jia ZF. 2019-nCoV transmission through the ocular surface must not be ignored. Lancet. 2020;395(10224):e39. doi:10.1016/S0140-6736(20)30313-5

4. Chen L, Liu M, Zhang Z, et al. Ocular manifestations of a hospitalised patient with confirmed 2019 novel coronavirus disease. $\mathrm{Br} \mathrm{J}$ Ophthalmol. 2020;104(6):748-751. doi:10.1136/bjophthalmol-2020316304

5. Cheema M, Aghazadeh H, Nazarali S, et al. Keratoconjunctivitis as the initial medical presentation of the novel coronavirus disease 2019 (COVID-19). Can J Ophthalmol. 2020;55(4):e125-9. doi:10.1016/j. jcjo.2020.03.003

6. Xia J, Tong J, Liu M, Shen Y, Guo D. Evaluation of coronavirus in tears and conjunctival secretions of patients with SARS-CoV-2 infection. J Med Virol. 2020;92(6):589-594. doi:10.1002/jmv.25725

7. Seah I, Agrawal R. Can the coronavirus disease 2019 (COVID-19) affect the eyes? A review of coronaviruses and ocular implications in humans and animals. Ocul Immunol Inflamm. 2020;28(3):391-395. doi:10.1080/09273948.2020.1738501

8. Sadhu S, Agrawal R, Pyare R, et al. COVID-19: limiting the risks for eye care professionals. Ocul Immunol Inflamm. 2020;1-7. doi:10.1080/09273948.2020.1755442

9. Hu K, Patel J, Patel BC. Ophthalmic Manifestations of Coronavirus (COVID-19). Treasure Island (FL): StatPearls Publishing; 2020. StatPearls [Internet].

10. Wu P, Duan F, Luo C, et al. Characteristics of ocular findings of patients with coronavirus disease 2019 (COVID-19) in Hubei Province, China. JAMA Ophthalmol. 2020;138(5):575. doi:10.1001/ jamaophthalmol.2020.1291

11. Peiris JS, Yuen KY, Osterhaus AD, Stohr K. The severe acute respiratory syndrome. $N$ Engl J Med. 2003;349(25):2431-2441. doi:10.1056/NEJMra032498

12. Loon SC, Teoh SC, Oon LL, et al. The severe acute respiratory syndrome coronavirus in tears. Br J Ophthalmol. 2004;88(7):861863. doi:10.1136/bjo.2003.035931

13. Mousavizadeh L, Ghasemi S. Genotype and phenotype of COVID19: their roles in pathogenesis [published online ahead of print, 2020 Mar 31]. J Microbiol Immunol Infect. 2020. doi:10.1016/j.jmii.20 20.03.022

14. Parrish RK, Stewart MW, Duncan PSL. Ophthalmologists are more than eye doctors-in Memoriam Li Wenliang. Am J Ophthalmol. 2020;213:A1-A2. doi:10.1016/j.ajo.2020.02.014

15. Ma QX, Shan H, Zhang HL, Li GM, Yang RM, Chen JM. Potential utilities of mask-wearing and instant hand hygiene for fighting SARS-CoV-2. J Med Virol. 2020;92(9):1567-1571. doi:10.1002/ jmv. 25805 .

16. Stroman DW, Mintun K, Epstein AB, et al. Reduction in bacterial load using hypochlorous acid hygiene solution on ocular skin. Clin Ophthalmol. 2017;11:707-714. doi:10.2147/OPTH.S132851

17. Reibaldi M, Avitabile T, Bandello F, et al. The effectiveness of $0.6 \%$ povidone iodine eye drops in reducing the conjunctival bacterial load and needle contamination in patients undergoing anti-VEGF intravitreal injection: a prospective, randomized study. J Clin Med. 2019;8 (7):E1031. doi:10.3390/jcm8071031

18. Kariwa H, Fujii N, Takashima I. Inactivation of SARS coronavirus by means of povidone-iodine, physical conditions and chemical reagents. Dermatology. 2006;212(Suppl 1):119-123. doi:10.1159/ 000089211

19. Ugazio E, Tullio V, Binello A, Tagliapietra S, Dosio F. Ozonated oils as antimicrobial systems in topical applications, their characterization, current applications, and advances in improved delivery techniques. Molecules. 2020;25(2):E334. doi:10.3390/molecules25020334

20. Sechi LA, Lezcano I, Nunez N, et al. Antibacterial activity of ozonized sunflower oil (Oleozon). J Appl Microbiol. 2001;90(2):279284. doi:10.1046/j.1365-2672.2001.01235.x 
21. Rowen RJ, Robins H. A plausible "penny" costing effective treatment for corona virus - ozone therapy. J Infect Dis Epidemiol. 2020;6:113.

22. Murray BK, Ohmine S, Tomer DP, et al. Virion disruption by ozonemediated reactive oxygen species. J Virol Methods. 2008;153(1):7477. doi:10.1016/j.jviromet.2008.06.004

23. Robbins SG, Detrick B, Hooks JJ. Ocular tropisms of murine coronavirus (strain JHM) after inoculation by various routes. Invest Ophthalmol Vis Sci. 1991;32(6):1883-1893.

24. Hooper LC, Chin MS, Detrick B, Hooks JJ. Retinal degeneration in experimental coronavirus retinopathy (ECOR) is associated with increased TNF-alpha, soluble TNFR2 and altered TNF-alpha signaling. J Neuroimmunol. 2005;166(1-2):65-74. doi:10.1016/j.jneuroim. 2005.05.018

25. Neri P, Pichi F. COVID-19 and the eye immunity: lesson learned from the past and possible new therapeutic insights. Int Ophthalmol. 2020;40(5):1057-1060. doi:10.1007/s10792-020-01389-2
26. Vardhana SA, Wolchok JD. The many faces of the anti-COVID immune response. $J$ Exp Med. 2020;217(6):e20200678. doi:10.10 $84 /$ jem. 20200678

27. Schoeman D, Fielding BC. Coronavirus envelope protein: current knowledge. Virol J. 2019;16:69.

28. Lopez L, Riffle A, Pike S, Gardner D, Hogue B. Importance of conserved cysteine residues in the coronavirus envelope protein. $J$ Virol. 2008;82(6):3000-3010. doi:10.1128/JVI.01914-07

29. Dussault PH, George AD, Trullinger TK. Peroxides as oxidative enzyme inhibitors: mechanism-based inhibition of a cysteine protease by an amino acid ozonide. Bioorg Med Chem Lett. 1999;9(22):32553258. doi:10.1016/S0960-894X(99)00563-6

30. Broer R, Boson B, Spaan W, Cosset FL, Corver J. Important role for the transmembrane domain of severe acute respiratory syndrome coronavirus spike protein during entry. $J$ Virol. 2006;80(3):13021310. doi:10.1128/JVI.80.3.1302-1310.2006

\section{Publish your work in this journal}

The International Medical Case Reports Journal is an international, peer-reviewed open-access journal publishing original case reports from all medical specialties. Previously unpublished medical posters are also accepted relating to any area of clinical or preclinical science. Submissions should not normally exceed 2,000 words or 4 published pages including figures, diagrams and references. The manuscript management system is completely online and includes a very quick and fair peer-review system, which is all easy to use. Visit http://www.dovepress.com/testimonials.php to read real quotes from published authors. 